\title{
Responsabilidade civil entre os cônjuges - o afastamento da fragilidade da garantia e o papel dos Tribunais
}

https://doi.org/10.21814/uminho.ed.30.8

\author{
Cristina Dias \\ Professora Associada com Agregação \\ Escola de Direito da Universidade do Minho
}

\section{Introdução}

A previsão de uma obrigação de indemnizar assente nos princípios gerais da responsabilidade civil por violação dos deveres conjugais era tradicionalmente afastada no nosso ordenamento jurídico, prevalecendo a teoria da fragilidade da garantia.

Paralelamente, entendia-se que a violação dos deveres conjugais tinha sanções específicas dentro do Direito da Família que afastavam a obrigação de indemnizar resultantes das regras gerais da responsabilidade civil. No domínio das relações familiares existem certos institutos, como o dever de assistência e a obrigação de alimentos, ou mesmo o divórcio e a separação de pessoas e bens, que tornariam dispensável o recurso a medidas que,"pela sua expressão material e egoísta, colidem com as exigências morais dos altos valores em jogo na sociedade conjugal"1,2.

As regras da responsabilidade civil (arts. $483 .^{\circ}$ e segs. do Código Civil) ${ }^{3}$ não se aplicariam no caso de violação dos deveres familiares pessoais, devendo fazer-se, consequentemente, uma interpretação restritiva daquelas regras gerais. Proteger-se-ia, assim, a família evitando que "as portas do santuário familiar" se abrissem aos tribunais.

A entrada em vigor da Lei $n .^{\circ} 61 / 2008$, de 31 de outubro, trouxe uma nova redação ao art. $1792 .^{\circ}$, consagrando no seu $n .^{\circ} 1$ a possibilidade de o cônjuge lesado poder

1 ANTUNES VARELA - Das Obrigações em Geral. Vol. I, 10. ${ }^{\text {a }}$ ed. Coimbra: Almedina, 2000, p. 200, nota 1. No mesmo sentido, Andrade, Manuel de - Teoria Geral das Obrigações. 3. ${ }^{a}$ ed. Coimbra: Almedina, 1966,

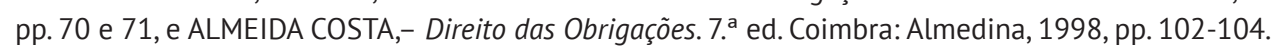

2 Em todo o caso, sempre se entendeu que o divórcio e a separação de pessoas e bens não eram verdadeiras sanções para a violação dos direitos pessoais conjugais. De facto, nem o divórcio nem a separação de pessoas e bens pretendem ser sanções contra o não cumprimento dos deveres conjugais, mas remédios para uma situação de vida matrimonial intolerável ou, mais exatamente, constatação da rutura do casamento - v., PEREIRA COELHO e OLIVEIRA, Guilherme de - Curso de Direito da Família. vol. I, 5. ${ }^{\text {a }}$ ed. Coimbra: Imprensa da Universidade de Coimbra, 2016, p. 183.

3 Sempre que sejam citados artigos, sem indicação expressa do diploma a que pertencem, a menção reporta-se ao Código Civil. 
intentar uma ação de responsabilidade civil contra o outro cônjuge, por violação dos deveres conjugais, nos termos gerais dos arts. $483 .^{\circ}$ e segs., e nos tribunais comuns.

Verificados os pressupostos da responsabilidade civil, poderá surgir uma obrigação de indemnizar por parte de um cônjuge violador dos deveres conjugais, ou seja, haverá lugar a indemnizações e a responsabilidade no âmbito dos direitos familiares? E como têm os nossos tribunais analisado o problema?

\section{Responsabilidade civil entre os cônjuges por violação dos deveres conjugais - o papel dos tribunais e a atual redação do art. 1792ํㅡㅁำ 1, do Código Civil}

Era no contexto da responsabilidade entre cônjuges por violação dos deveres conjugais que predominava a doutrina da fragilidade da garantia. Os deveres familiares pessoais (arts. $1672 .^{\circ}$ e segs.) não estariam sujeitos à tutela mais consistente dos deveres jurídicos, que é a possibilidade de o credor exigir do devedor o seu cumprimento e/ou obter deste uma indemnização. Tratar-se-ia de deveres, de relações de carácter tão íntimo, tão privado que seria impossível forçar, externamente, a sua observância.

Assim, perante casos de incumprimento dos deveres conjugais, a única possibilidade que assistia ao lesado era dissolver o vínculo, sendo inaceitável um pedido de indemnização na hipótese de violação de qualquer dos deveres recíprocos dos cônjuges ${ }^{4}$. Tratar-se-ia de uma tutela jurídica exclusivamente familiar.

Até à Lei n. ${ }^{\circ} 61 / 2008$, de 31 de outubro, que deu nova redação ao art. $1792 .^{\circ}$, o direito português não previa uma ação de responsabilidade civil especificamente pela violação dos deveres conjugais, limitando-se ao princípio geral disposto no art. 483. ${ }^{\circ}$, n. ${ }^{0} 1$.

Progressivamente a doutrina e a jurisprudência passaram a admitir que um dos cônjuges pudesse intentar uma ação de responsabilidade civil contra o outro cônjuge por violação dos deveres conjugais, gerando uma obrigação de indemnizar que, verdadeiramente, será a sanção para o não cumprimento dos deveres matrimoniais, pois essa sanção não é o divórcio 5 .

4 Criticando a teoria da fragilidade da garantia, v., HÖRSTER, Heinrich - A Respeito da Responsabilidade Civil dos Cônjuges entre Si (ou: A Doutrina da "Fragilidade da Garantia" será Válida?). "Scientia luridica". Tomo XLIV, n. ${ }^{\circ}$ 253/255, 1995, pp. 113-124, CERDEIRA, Ângela - Da responsabilidade civil dos cônjuges entre si. Coimbra: Coimbra Editora, 2000, pp. 82 e segs., DIAS, Cristina - Responsabilidade civil e direitos familiares conjugais (pessoais e patrimoniais). "Scientia luridica". Tomo XLIX, nos 286/288, 2000, pp. 351-374, e PEREIRA COELHO e OLIVEIRA, Guilherme de - ob. cit., pp. 155-157.

5 PEREIRA COELHO e OLIVEIRA, Guilherme de - ob. cit., p. 155. 
A consideração da essência ética do casamento, a defesa da paz familiar, a ideia de evitar uma excessiva intervenção do tribunal na vida familiar ${ }^{6}$ não podem excluir a obrigação de indemnizar no caso de violação dos direitos familiares pessoais. Saliente-se que o cônjuge lesado deve poder pedir ao outro uma indemnização quer pelos danos patrimoniais quer pelos não patrimoniais (art. $496^{\circ}$ ); e quer pelos danos resultantes diretamente dos factos que servem de fundamento ao divórcio quer pelos danos resultantes do próprio divórcio, e que são consequência indireta daqueles factos.

Mesmo antes da Lei n. ${ }^{\circ} 61 / 2008$, de 31 de outubro, o art. $1792 .^{\circ}$ já admitia que o cônjuge declarado único ou principal culpado no divórcio devia reparar os danos não patrimoniais causados ao outro cônjuge pela dissolução do casamento (sofrimentos ocasionados pelo divórcio, desconsideração social...). Não previa era a possível indemnização resultante da violação dos deveres conjugais que eram causa do divórcio.

Sempre se aceitou que a violação dos deveres conjugais pudesse implicar, ao mesmo tempo, uma violação de outro bem jurídico, como a violação de um direito de personalidade. Esta violação de um direito autónomo faria incorrer o lesante, o cônjuge faltoso, em responsabilidade civil e, se fosse caso disso, em responsabilidade penal, como acontece com lesões corporais, não obstante o carácter íntimo da vida familiar. Nestes casos, a fragilidade da garantia era contornada por força da sanção provocada pela violação simultânea de um outro direito subjetivo privado em relação ao qual a garantia funcionava.

Todavia, tal simultaneidade poderá não existir. Era aqui que se colocava a questão de saber se ao cônjuge lesado restava apenas como sanção o divórcio, afastando-se as regras gerais da responsabilidade civil.

Como se sabe, o divórcio não é concebido como sanção, mesmo antes da recente alteração legislativa ao regime jurídico do divórcio. Por outro lado, pese embora a sua natureza sui generis, os direitos familiares pessoais são direitos privados, o que significa que thes subjaz o binómio liberdade/responsabilidade. Esta consequência da responsabilidade não pode ficar afastada pelo facto de o sujeito do direito e o sujeito do dever se encontrarem casados.

Nada impede a aplicação dos meios comuns à tutela dos deveres conjugais pessoais, não podendo a celebração do casamento abrir um regime de exceção ao regime geral da responsabilidade civil. Assim, a tutela jus-familiar dos deveres conjugais é compatível com a responsabilidade civil comum?

A nossa jurisprudência seguiu no mesmo sentido.

6 Razões que justificavam, ou podiam justificar, uma interpretação restritiva do art. $483 .^{\circ}$, em termos de aí não se abrangerem os direitos familiares pessoais. Para uma análise das razões apresentadas para justificar a doutrina da fragilidade da garantia, v., PINHEIRO, Jorge Duarte - O núcleo intangível da comunhão conjugal. Os deveres conjugais sexuais. Coimbra, Almedina, 2004, pp. 568 e segs.

7 V., PINHEIRO, Jorge Duarte - ob. cit., pp. 677-692. 
De referir o acórdão do S.T.J., de 13.03.1985 (B.MJ., n. ${ }^{\circ} 345 .^{\circ}, 1985$, p. 414), onde se afirma que 0 art. $1792 .^{\circ}$, na sua anterior redação, compreende unicamente os danos não patrimoniais causados pelo próprio divórcio, devendo o respetivo pedido de indemnização ser obrigatoriamente formulado na ação de divórcio. Os danos ocasionados diretamente pelos factos em que se fundamenta o divórcio, sejam de natureza patrimonial ou não, podem dar lugar à obrigação de indemnizar, nos termos do art. $483 .^{\circ}$. Aqui se refere ainda que, para além dos alimentos, e a coberto do princípio geral correspondente ao atual art. $483 .^{\circ}$, o cônjuge culpado do divórcio podia ser compelido a indemnizar o outro dos danos morais e patrimoniais causados, visto os atos culposos que servem de fundamento ao divórcio ofenderem os direitos familiares pessoais do cônjuge inocente. Seria nesta obrigação de indemnizar que estaria, verdadeiramente, a sanção para o não cumprimento dos deveres matrimoniais.

No mesmo sentido, devem referir-se os acórdãos do S.T.J., de 18.02 .1986 (B.MJ., n. ${ }^{\circ}$ 354. ${ }^{\circ}, 1986$, p. 567), 23.03 .1988 (B.M.J., n. ${ }^{\circ} 375 .^{\circ}, 1988$, p. 390), de 15.06 .1993 (Col. Jurisp., tomo 2, 1993, p. 154), e de 28.05 .1998 (B.M.J., n. ${ }^{\circ} 477 .^{\circ}, 1998$, p. 518 ), dos quais pode concluir-se que 0 art. $1792^{\circ}$ (na redação então vigente) apenas compreendia os danos não patrimoniais causados pelo próprio divórcio, sem prejuízo de os demais poderem ser reparados em processo comum de declaração e com fundamento na responsabilidade civil a que se reporta o art. $483^{\circ}$.

0 acórdão do S.T.J., de 26.06 .1991 (B.MJ., n. ${ }^{\circ} 408 .^{\circ}, 1991$, p. 538), debruça-se sobre a reparação dos danos causados pelos factos fundamento do divórcio, por si só, ainda que no âmbito da ressarcibilidade dos danos morais. Aqui se determinou que a violação dos deveres conjugais por parte de um dos cônjuges (no caso em análise o cônjuge culpado era o marido, pela violação dos deveres de respeito e coabitação) provoca sofrimento, dor e, muitas vezes, traumatismos prolongados. Esta dor e sofrimento constituem danos não patrimoniais e são indemnizáveis, nos termos dos arts. 483. ${ }^{\circ}$ e $496 .^{\circ}$. Foi, assim, em ação autónoma ao divórcio, concedida uma indemnização pelos danos resultantes da violação dos deveres conjugais (neste caso, danos não patrimoniais).

De igual modo, têm-se pronunciado os tribunais da Relação sobre a matéria em análise. Cfr., entre outros, os acórdãos da RP, de 07.02 .1980 (Col. Jurisp., tomo 1, 1980, p. 29), de 31.07.1980 (B.M.J., n. ${ }^{\circ} 303 .^{\circ}$, 1981, p. 271), de 20.10 .1988 (Col. Jurisp., tomo 4, 1988, p. 201 - que, tal como o acórdão do STJ, de 26.06 .1991 (loc. cit.), também atribuiu, em ação autónoma à de divórcio, uma indemnização pela violação dos deveres conjugais), e de 08.03.1999 (Col. Jurisp., tomo 2, 1999, p.176), e da RC, de 04.04.1995 (B.M.J., n. ${ }^{\circ} 446 .^{\circ}, 1995$, p. 361).

Podemos, da análise da jurisprudência abordada, concluir que, tal como certa doutrina, também os nossos tribunais admitiam ações de responsabilidade civil, nos termos dos arts. $483 .^{\circ}$ e segs., por violação dos direitos familiares pessoais, afastando-se da doutrina tradicional da fragilidade da garantia. Não obstante, não deixa de ser curioso que, muito embora esta conclusão decorra das decisões dos nossos tribunais, pouca jurisprudência (de referir os acórdãos do STJ, de 26.06.1991, e da RP, de 
20.10.1988) se encontrava que, em ação autónoma à ação de divórcio, concedesse uma indemnização por violação dos deveres conjugais que fundamentasse o pedido de divórcio.

Com a Lei n. ${ }^{\circ} 61 / 2008$, de 31 de outubro, o cônjuge lesado pode requerer, nos termos gerais da responsabilidade civil (arts. $483 .^{\circ}$ e segs.), e não na ação de divórcio, a reparação dos danos causados pelo outro cônjuge (art. $1792 .^{\circ}$, n. ${ }^{\circ}$ 1). Na ação de divórcio são apenas indemnizados os danos não patrimoniais causados ao cônjuge pela dissolução do casamento requerida pelo outro cônjuge por alteração das faculdades mentais daquele (arts. $1792 .^{\circ}$, n. $^{\circ} 2$, e $1781 .^{\circ}$, al. $b$ )). Ao admitir a possibilidade de um cônjuge intentar uma ação de responsabilidade civil contra o outro afastam-se os resquícios ainda existentes da teoria da fragilidade da garantia, admitindo o funcionamento das regras da responsabilidade civil por incumprimento dos deveres conjugais ${ }^{8}$.

Não podemos, todavia, deixar de referir que nem todos os autores concordam com este entendimento.

No sumário do acórdão do STJ, de 12.05.2016 (http://www.dgsi.pt, consultado em 2021-04-07), pode ler-se o seguinte:

“I - Sob a vigência do art. 1792. ${ }^{\circ}$ do CC (...), no que respeita à admissibilidade do direito a indemnização por danos decorrentes da violação dos deveres conjugais pessoais, desenhavam-se, na doutrina nacional, duas perspetivas:

i) uma de cariz tradicional, no sentido de negar tal direito, ancorada na tese da denominada fragilidade da garantia daqueles deveres;

ii) outra, a sustentar a possibilidade de indemnização do cônjuge lesado, em ação autónoma à do divórcio, mesmo na constância do casamento, nos termos gerais da responsabilidade civil, considerando que os direitos conjugais revestiam a natureza jurídica de direitos subjetivos, não se justificando que a sua função institucional pudesse desmerecer aquela tutela.

8 Neste sentido, v., por exemplo, HÖRSTER, Heinrich - A Respeito da Responsabilidade Civil dos Cônjuges... loc. cit., pp. 113-124, e A responsabilidade civil entre os cônjuges. in AAVV. "E foram felizes para sem-

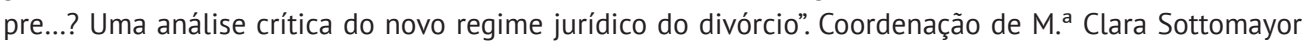
e M. ${ }^{a}$ Teresa Féria de Almeida. Coimbra: Coimbra Editora/Wolters Kluwer, 2010, pp. 108-110; XAVIER, Rita Lobo - Recentes alterações ao regime jurídico do divórcio e das responsabilidades parentais - Lei $n^{\circ}$ 61/2008, de 31 de Outubro. Coimbra: Almedina, 2009, p. 37, e Direito ao divórcio, direitos recíprocos dos cônjuges e reparação dos danos causados: liberdade individual e responsabilidade no novo regime do divórcio. In "AAVV. Estudos em homenagem ao Professor Doutor Heinrich Ewald Hörster". Coimbra: Almedina, 2012, pp. 499 e segs.; DIAS, Cristina - Uma análise do novo regime jurídico do divórcio (Lei n. ${ }^{\circ}$ 61/2008, de 31 de Outubro). 2. ${ }^{a}$ ed. Coimbra: Almedina, 2009, pp. 23 e 24, e Breves notas sobre a responsabilidade civil dos cônjuges entre si: o novo regime do art. $17922^{\circ}$ do Código Civil (na redacção dada pela Lei n. ${ }^{\circ}$ 61/2008, de 31 de Outubro) e a manutenção da irresponsabilidade ao nível dos efeitos patrimoniais do casamento. in AAVV. "Estudos dedicados ao Professor Doutor Luís Alberto Carvalho Fernandes, Direito e Justiça”. Vol. I. Lisboa: Universidade Católica Editora, 2011, pp. 389-419; PINHEIRO, Jorge Duarte - ob. cit., pp. 760 e segs., e O Direito da Família Contemporâneo. 7. ${ }^{a}$ ed. Coimbra: Gestlegal, 2020, pp. 465 e segs; e CAMPOS, Diogo e CAMPOS, Mónica Martinez de - Lições de Direito da Família. 3. ${ }^{a}$ ed. Coimbra: Almedina, 2016, pp. 352-354. 
II - Por sua vez, a jurisprudência foi abrindo caminho e sedimentando a orientação desta segunda perspetiva.

III - Com a entrada em vigor da Lei n. ${ }^{\circ} 61 / 2008$, de $31-10$, e face à nova redação dada ao art. $1792 .{ }^{\circ}$ do CC, reforçou-se a tese da $2 .^{\text {a }}$ perspetiva, embora existam ainda alguns autores a sustentar, face à abolição do divórcio-sanção, que a violação dos deveres conjugais pessoais deixou de merecer a tutela direta por via do instituto geral da responsabilidade civil.

IV - Por sua vez, a jurisprudência tem mantido a linha que vinha seguindo, no sentido da admissibilidade daquela tutela, nomeadamente em sede de indemnização dos danos não patrimoniais, desde que, pela sua gravidade, mereçam a tutela do direito nos termos do art. $496 .^{\circ}$, n. $^{\circ} 1$, do CC.

V - Assim, pelo menos em caso de concomitância de violação dos deveres conjugais pessoais e dos direitos de personalidade do cônjuge lesado, impõe-se reconhecer a admissibilidade do direito a indemnização com base nos termos gerais da responsabilidade civil".

Este ponto $\mathrm{V}$ gerou alguma controvérsia na sua interpretação no sentido de saber se deveria admitir-se uma ação de responsabilidade civil apenas quando a violação dos deveres conjugais implicasse uma violação dos direitos de personalidade do cônjuge lesado.

Francisco Brito Pereira Coelho, na anotação que faz ao referido acórdão, entende que a responsabilidade a que se refere o art. $1792 .^{\circ}$ apenas ocorre se paralelamente à violação de um dever conjugal houver violação de um direito de personalidade do cônjuge 9 . A reforma do regime jurídico do divórcio, na Lei n. ${ }^{\circ} 61 / 2008$, traduziu-se numa nova forma de encarar o casamento, deixando este de implicar o cumprimento de uma série de deveres conjugais, e passando estes deveres conjugais do art. $1672 .^{\circ}$ a uma "categoria dogmática diversa do dever jurídico"10.

No mesmo sentido pronuncia-se Guilherme de Oliveira. Escreve este autor que a Lei n. ${ }^{\circ} 61 / 2008$, de 31 de outubro, alterando o regime jurídico do divórcio, deixou dúvidas no texto do art. 1792..: "faltou a menção expressa de que se pretendia apenas aplicar o regime da responsabilidade extracontratual". A doutrina e a jurisprudência dominantes têm defendido a plena aplicação de toda a responsabilidade civil, incluindo a responsabilidade contratual por violação dos deveres conjugais, ainda que os atos não tenham ofendido direitos de personalidade do lesado. Considera, todavia, o autor que a norma deve ser objeto de uma interpretação restritiva, para excluir a aplicação da responsabilidade contratual. "A responsabilidade civil intervirá, somente, quando as violações dos deveres conjugais implicarem também ofensas

9 PEREIRA COELHO, Francisco Brito - STJ - Acórdão de 12 de maio de 2016: Deveres conjugais e responsabilidade civil - estatuto matrimonial e estatuto pessoal (não matrimonial) dos cônjuges. "Revista de Legislação e de Jurisprudência”. Ano 147. ${ }^{\circ}$, n. ${ }^{\circ}$ 4006, Set-Out., 2017, pp. 54-67.

10 Mesmo autor e obra, p. 64. 
dos direitos de personalidade do lesado; intervirá, portanto e apenas, o regime da responsabilidade delitual" ${ }^{\prime 1}$. Exclui, portanto, a responsabilidade obrigacional atendendo à ausência de uma vinculação jurídica que se atribua aos deveres conjugais; e a responsabilidade extracontratual apenas ocorrerá no caso de lesão de outros bens jurídicos (como direitos de personalidade) ${ }^{12}$.

Ou seja, a violação de deveres conjugais em si não geraria qualquer responsabilidade, implicando apenas consequências endofamiliares. A ser assim teríamos um regresso à teoria da fragilidade da garantia. Julgamos que o objetivo de uma interpretação como esta é apenas a de desvalorização dos deveres conjugais mas que não nos parece ter suporte legal no nosso ordenamento jurídico atual.

Neste sentido pronunciou-se, também em anotação ao mesmo acórdão, Rute Teixeira Pedro, considerando que, atendendo ao art. $1792 .^{\circ}$, n. $^{\circ} 1$, "um cônjuge pode responder perante o outro por danos advenientes de atos que seriam ilícitos fora do contexto familiar, bem como por atos, cujo desvalor advém de terem sido praticados por quem está vinculado por força do compromisso jurídico matrimonial e pelos deveres a ele inerentes (...). Assim, quanto aos atos que seriam ilícitos fora do contexto familiar, atentatórios de posições jurídicas não familiares (por exemplo, do direito à vida, do direito à integridade física, ...), o facto de o lesante e lesado estarem ligados por um vínculo familiar - no caso conjugal - não deve ditar a exclusão do funcionamento da responsabilidade civil. E seria, assim, independentemente do teor normativo atual do art. $1792 .^{\circ}$, n. $^{\circ} 1$, já que a proteção conferida pelo art. $483 .^{\circ}$, n. $^{\circ} 1$, aos bens de personalidade não pode ser travada pelo contexto conjugal de produção dos danos. Quando o ato desvalioso consubstancia uma violação dos deveres familiares (conjugais) a cujo cumprimento aquele cuja responsabilidade se equaciona está vinculado na qualidade de cônjuge do lesado, pensamos que dois caminhos são equacionáveis para fundar a sua responsabilidade" ${ }^{13}$. Assim, considera a autora que é possível, por um lado, o recurso ao art. $483 .^{\circ}$, n. $^{\circ} 1$, no caso de um cônjuge praticar um ato que se traduza na violação de deveres conjugais independentemente de, no caso concreto, se ter verificado uma violação de outro direito absoluto pessoal (p. ex., a integridade física). Não é, por isso, de limitar a ressarcibilidade dos danos decorrentes do incumprimento dos deveres conjugais às hipóteses de concomitância de violação dos deveres conjugais pessoais e dos direitos de personalidade do cônjuge lesado.

11 OLIVEIRA, Guilherme de - Responsabilidade civil por violação dos deveres conjugais, [consultado em 2021-04-07], disponível em http://www.guilhermedeoliveira.pt/resources/Responsabilidade-civil-porviolação-dos-deveres-conjugais.pdf.

12 Ao contrário do entendimento de PINHEIRO, Jorge Duarte - O núcleo intangível da comunhão conjugal..., ob. cit., p. 760, para quem a celebração do casamento não cria uma "área de excepção" relativamente à aplicação dos meios comuns à tutela dos deveres conjugais, OLIVEIRA, Guilherme de - Responsabilidade civil por violação dos deveres conjugais. loc. cit., p. 24, considera que "o casamento é, de facto, uma área de exceção".

13 PEDRO, Rute Teixeira - A responsabilidade civil como (derradeira) manifestação de juridicidade dos deveres conjugais? - anotação ao Ac. do STJ, de 12.05.2016. "Cadernos de Direito Privado". N. ${ }^{\circ}$ 61, janeiro-março, 2018, pp. 52-62. 
Por outro lado, não afasta a possibilidade de recurso às regras da responsabilidade obrigacional, por tal entendimento se coadunar "com a conceção de casamento, como relação contratual matrimonial, que, hoje, consideramos vigente entre nós"14.

Não cremos, pelo que já referimos, que a eliminação da violação culposa dos deveres conjugais como fundamento do divórcio implique um desvalor dos deveres conjugais e do seu incumprimento, afetando a juridicidade de tais deveres. Estamos, por isso, plenamente de acordo com a posição adotada pela última autora citada e que, aliás, já havíamos expressado em trabalhos anteriores.

\section{Nota final}

Apesar da controvérsia doutrinal a propósito da tutela exclusivamente familiar dos deveres conjugais, nomeadamente, com o divórcio, e a interpretação restritiva proposta por alguns autores para o art. $1792 .^{\circ}$, pode o cônjuge lesado nos seus direitos (conjugais) recorrer às regras gerais da responsabilidade civil (extracontratual e, eventualmente, contratual), independentemente da violação de outros direitos absolutos pessoais. É isto que decorre da redação do art. $1792^{\circ}$ e é esse o percurso que tem vindo a ser seguido pela nossa jurisprudência.

14 Ibidem, p. 62, citando outra obra da autora (Convenções matrimoniais: a autonomia na conformação dos efeitos patrimoniais do casamento. Coimbra: Almedina, 2018, pp. 273 e segs.). 